\title{
Lugares de fala contra o sexismo da campanha ElesPorElas: análise do discurso organizacional
}

Places of speech against the sexism of the HeForShe campaign: an organizational discourse analysis

Lugares de enunciación contra el sexismo de la campaña ÉlPorElla: análisis del discurso organizacional

(9) Phillipp Dias Gripp

- Doutor pelo Programa de Pós-Graduação em Comunicação da Universidade Federal de Santa Maria (POSCOM/UFSM).

- Mestre POSCOM/UFSM.

- E-mail: phidgripp@gmail.com

(9) Ada Cristina Machado Silveira

- Professora titular do POSCOM/UFSM.

- Pesquisadora do CNPq.

- Colaboradora do mestrado profissional em Comunicação e Indústria Criativa da Universidade Federal do Pampa (Unipampa).

- E-mail: ada.silveira@ufsm.br 


\section{Resumo}

O artigo examina o discurso organizacional do movimento pela igualdade de gênero HeForShe/ElesPorElas da ONU Mulheres, com atenção ao debate sobre lugares de fala. Embasando-se na semiótica discursiva paratextual de contextualização sóciohistórica e enunciativa, a análise é feita por meio de três estratégias: 1) contextualização histórica e identidade visual; 2) protagonismo feminino e convite à cooperação masculina; e 3) implementação e alcance da campanha. Evidencia-se que a prática discursiva da ElesPorElas envolve homens como agentes na luta contra o sexismo e se sustenta pelo feminismo visionário.

\section{PALAVRAS-CHAVE: DISCURSO • GÊNERO • RELAÇÕES DE PODER • LUGAR DE FALA • ELESPORELAS.}

\section{Abstract}

This article analyzes the organizational discourse of the HeForShe movement, built by the UN Women, minding the debate on places of speech. Based on the paratextual discursive semiotics of sociohistorical and enunciative contextualization, the analysis was performed by three analytical strategies: historical contextualization and visual identity; female protagonism and invitation to male cooperation; and campaign implementation and reach. The results indicate that HeForShe discursive practice is sustained by visionary feminism, involving men as agents in the fight against sexism.

KEYWORDS: DISCOURSE • GENDER •POWER RELATIONS • PLACE OF SPEECH • HEFORSHE.

\section{Resumen}

Este artículo analiza el discurso organizativo del movimiento HeForShe/ÉlPorElla de ONU Mujeres, con atención al debate sobre los lugares de enunciación. Con base en la semiótica discursiva paratextual de contextualización sociohistórica y enunciativa, se realiza un análisis de estas tres estrategias: 1) la contextualización histórica e identidad visual; 2) el protagonismo femenino e invitación a la cooperación masculina; y 3) la implementación y alcance de la campaña. Es evidente que la práctica discursiva de ÉlPorElla involucra a los hombres como los agentes en la lucha contra el sexismo y se sustenta en el feminismo visionario. 


\section{INTRODUÇÃO}

$\mathrm{D}$ jamila Ribeiro assinala que a noção de "lugar de fala" emerge como uma ferramenta que visa romper ordenações de que apenas pessoas com autoridade prévia poderiam falar a respeito de assuntos diversos, mas que também gera interdições, a exemplo da frase: "'fique quieto, esse não é seu lugar de fala'" (2017, p.56). A autora explica que a origem do termo é incerta e sua fundamentação não está determinada por uma epistemologia específica. Ribeiro (2017) pondera 0 lugar de fala pelo ponto de vista feminista, mas aponta que é possível embasá-lo através de diferentes correntes teóricas: estudos psicanalíticos, comunicacionais, outras vertentes feministas, raciais e decoloniais.

Diante da ainda atual carência epistemológica e rasa pluralidade do debate teórico acerca do termo, fundamentamos, em trabalho anterior, os lugares de fala por meio da argumentação foucaultiana e butleriana de relações de poder e discurso, além de destacarmos a dimensão identitária mobilizada pela noção (Gripp; Silveira, 2021). Esta reflexão definiu a noção como uma estratégia enunciativa que aliança a fala do sujeito à identidade temporariamente assumida por ele em situações de comunicação. Tal abordagem (Gripp; Silveira, 2021) encontrou proficuidade especialmente nas análises de situações comunicacionais em que sujeitos são convocados a falar e agir em conjunto nas lutas de outrem. Em Gripp e Silveira (2021), problematizamos o uso da noção ao evidenciarmos sua ambivalência: 1) representacional na manifestação de recusas e interdições enunciativas; e 2) discursiva na sua expressão dialógica.

Com base em tal fundamentação (Gripp; Silveira, 2021), este artigo examina o discurso organizacional do movimento pela igualdade de gênero HeForShe/ElesPorElas da ONU Mulheres para atentar aos debates sobre lugares de fala e combate ao sexismo nas relações de gênero. Observamos as estratégias discursivas e institucionais praticadas pelo movimento e, com isso, buscamos evidenciar os balizadores de seu discurso, possíveis produções de sentidos e o lugar de fala de homens e mulheres nas lutas pela igualdade de gênero na visão da ONU Mulheres.

0 discurso organizacional do movimento é examinado pela diretriz da semiótica discursiva em âmbito paratextual de contextualização sócio-histórica e enunciativa, alicerçado no modelo proposto por Duarte e Castro (2014). A paratextualidade reconhece que os textos mantêm relações com o entorno e as marcas discursivas dessa relação são recuperadas na análise, por meio de estratégias que identificam e descrevem a história, a configuração sociocultural e da identidade do objeto empírico, além dos/as responsáveis pela produção enunciativa e do público-alvo, com o objetivo de preservar e promover a marca (Duarte; Castro, 2014). Para tanto, observamos publicações do site do ElesPorElas na internet, o enunciado de lançamento proferido por Emma Watson e entrevistamos Nadine Gasman, representante da ONU Mulheres no Brasil, sobre a campanha. Após a análise paratextual, interpretamos e avaliamos os dados identificados.

Diante disso, 0 artigo se divide em três seções de caráter analítico, a fim de evidenciar o discurso organizacional do ElesPorElas, com destaque aos debates sobre lugar de fala e relações de gênero. As seções foram nomeadas conforme os critérios de análise que ressaltam as marcas paratextuais do movimento: contextualização histórica e da identidade visual; protagonismo feminino e convite à cooperação masculina; estratégias de implementação e alcance da campanha. Optamos, então, por apresentar a interpretação dos dados e a avaliação em conjunto às considerações finais. 


\section{CONTEXTUALIZAÇÃO HISTÓRICA E DA IDENTIDADE VISUAL}

O movimento HeForShe, traduzido no Brasil como ElesPorElas, foi lançado mundialmente no dia 20 de setembro de 2014 na sede da Organização das Nações Unidas (ONU) em Nova York. Constitui-se como um meio de implementação do Plano Estratégico Global da ONU Mulheres (2014-2017), que foi desenvolvido com base nas conclusões aprovadas em 2004, na 48a Sessão da Comissão das Nações Unidas sobre a Situação das Mulheres. A Sessão deu destaque à participação dos homens nas mobilizações pela igualdade de gênero e solicitou que eles exerçam papéis e responsabilidades na causa (ONU Mulheres, 2015a).

A Comissão sobre a Situação das Mulheres, conforme Raewyn Connell (2016), é uma das mais antigas agências da ONU datada de 1940 - e das maiores reuniões anuais de lideranças globais que objetivam discutir os direitos das mulheres. Connell (2016) aponta que parte das ONG participantes do evento de 2004 não estavam satisfeitas com o foco da reunião em homens e meninos, pois se atinham à visão de que eles seriam exclusivamente perpetradores de violência. Porém, alguns consensos foram registrados no documento de orientações de políticas públicas da 48a Sessão sobre Situação das Mulheres, denominado "O papel de homens e meninos na conquista da igualdade de gênero". 0 documento é o primeiro amplo acordo internacional definido sobre o assunto, que "[...] criou uma referência para futuras discussões sobre igualdade de gênero, apresentando a igualdade de gênero como um projeto positivo para os homens" (Connell, 2016, p.112).

A marca do HeForShe, então, foi elaborada com a proposta de ilustrar o conceito de convite à participação dos homens nas lutas contra o sexismo. 0 site do movimento explica que a marca foi pensada ao considerar os tradicionais símbolos que

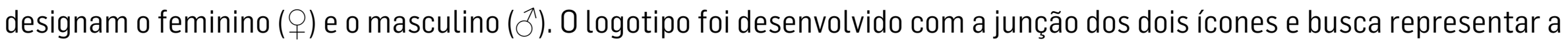
luta pela igualdade de gêneros em benefício de todas/os através da união entre sujeitos de gêneros diferentes. A união dos símbolos na construção do logotipo e suas características podem ser vistas na Figura 1.

Figura 1: Marca da campanha ElesPorElas/HeForShe

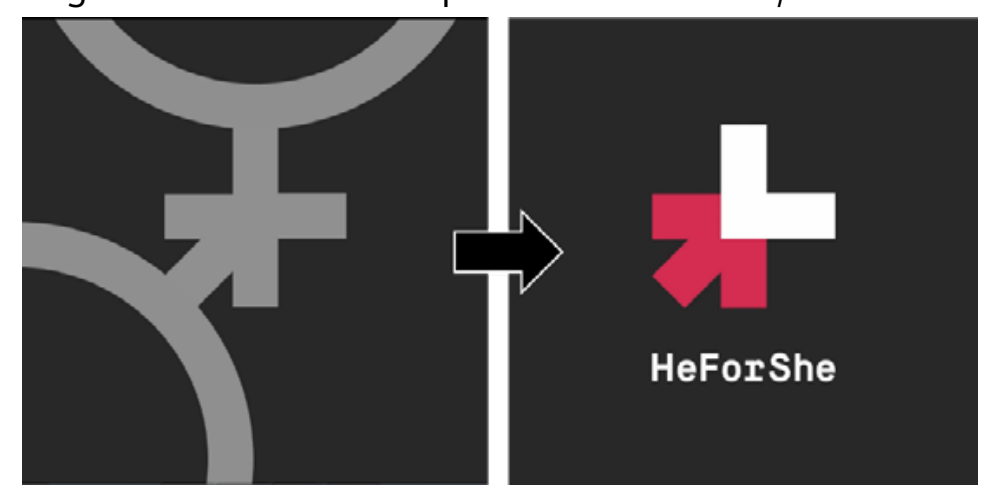

Fonte: https://www.heforshe.org/pt-br.

O logotipo contrasta de forma dinâmica a cor magenta no símbolo masculino e o branco no feminino em um fundo cinza escuro. Conforme o site, a escolha pelo destaque do magenta expressa juventude, energia e ação, além de paixão e estímulo. Ao ter em conta que a cor magenta é geralmente associada ao gênero feminino, acreditamos que a opção de utilizá-la no símbolo masculino demonstra a tentativa de desconstrução de estereótipos sociais e a defesa de que características julgadas como femininas também sejam manifestadas por homens, além de indicar que eles poderiam levar expressividades da cor - uma nova energia, ação, paixão e estímulo - à luta contra o sexismo.

Em 2015, a página oficial do movimento na internet explicava que as lutas por igualdade de gênero foram criadas e lideradas por e para as mulheres, mas que homens já começavam a participar de ações e debates sobre o tema. Em 2016, a página teve configurações no layout e este fragmento foi excluído. Mais abaixo, na mesma aba, ficavam expostas dinamicamente frases de apoio às lutas feministas de homens reputados como influentes no âmbito social internacional, também excluídas. Nesse 
encadeamento de mudanças no site, aponta-se que os textos oficiais fornecidos entre 2014 e 2015 para explicar o HeForShe e que servem de base para a escrita desta análise paratextual eram versões em inglês ou espanhol. Eles foram substituídos em 2015 por traduções para o português. Salientamos que os documentos se referem ao ElesPorElas ora como campanha ora como movimento, por isso também são utilizadas as duas designações neste trabalho. Informações se repetem nos documentos e diferem-se em apontamentos relacionados às especificidades dos públicos-alvo.

Para o desenvolvimento da análise paratextual e para esclarecer dúvidas sobre a ElesPorElas, realizamos uma entrevista por e-mail com Nadine Gasman em julho de 2017. Quando questionada sobre o que motivou a criação da campanha, ela explica que o objetivo era "reunir pessoas de todos os sexos, gêneros, raças, etnias e classes sociais num esforço global para a remoção das barreiras sociais e culturais que limitam as mulheres e as impedem de usufruir de seus direitos humanos" (Gasman, 2017, p.1).

A campanha foi lançada na reunião de setembro através de um proferimento da atriz britânica Emma Watson, nomeada Embaixadora da Boa Vontade da ONU Mulheres em março de 2014. Watson (Emma..., 2014) se dirigiu às autoridades e convidados/as presentes pedindo ajuda para pôr fim à desigualdade de gênero, avaliando que, para isso ser tangível, é necessário o envolvimento de todas/os. Então, ela explica que a campanha objetiva mobilizar cada vez mais homens e meninos a participarem dessa mudança e ressalta que o HeForShe é o primeiro movimento desenvolvido pela ONU que se caracteriza pelo direcionamento do debate sobre igualdade de gênero também aos homens. Diante disso, a atriz os convidou a assumirem um papel a favor da luta pela igualdade de gênero, para que tanto as mulheres como os homens se beneficiem. Emma argumenta que o objetivo do HeForShe é alcançar a união.

Ao fim de sua fala, ela convoca os homens a se mobilizarem na luta e a refletirem: "Se não eu, quem? Se não agora, quando?" (Emma..., 2014). Essas perguntas se tornaram o slogan da campanha e são apresentadas e difundidas em diversos âmbitos nos quais a HeForShe é promovida e veiculada. No enunciado de lançamento, a atriz expõe que tais questões surgiram em momentos de dúvida e nervosismo sobre sua fala e seu direito de estar ali. Ao se entender como privilegiada em diferentes aspectos e considerar outras pessoas que talvez desempenhariam melhor aquele papel, ela admite que o seguinte estímulo a fez aceitar o desafio: não fosse ela, quem estaria ali, se não naquele momento, quando?

Consta-se que o slogan que aparece em divulgações da campanha é uma reverberação do enunciado de Emma. Há, por conseguinte, a reiteração e apropriação de outra voz que não apenas as que estão aparentemente presentes em textos de difusão da ElesPorElas: a voz de Emma. Gasman (2017, p.2), quando questionada sobre a aceitação da ElesPorElas pelo público, ressaltou e justificou a importância da fala da atriz:

A aceitação da ElesPorElas [...] tem sido muito grande e positiva desde o dia do seu lançamento com o discurso da [...] Emma Watson, por ela ter trazido argumentos com os quais as pessoas se identificam imediatamente, o que levou à viralidade do seu discurso. Ela mostrou que a pressão social que impõe aos homens formas hegemônicas de masculinidades faz com que eles se tornem opressores e, consequentemente, as mulheres sejam oprimidas.

É possível reconhecer, então, o HeForShe como um movimento global de luta contra o sexismo que busca auxiliar os homens a reconhecerem as pressões sociais que sofrem por conta das formas hegemônicas de masculinidades vigentes, bem como seus privilégios e consequentes opressões às mulheres. Diante disso, convoca-os a cooperarem com elas nas lutas pela igualdade de gêneros, mas importa atentar que a campanha não pretende que elas percam o protagonismo das lutas. 


\section{PROTAGONISMO FEMININO E CONVITE À COOPERAÇÃO MASCULINA}

A ElesPorElas reconhece que os movimentos de mulheres obtiveram avanços importantes em reivindicações relacionadas à saúde, educação, economia e participação política, mas que a igualdade de gênero ainda precisa ser alcançada no mundo. A ONU Mulheres (2015a, p.1) destaca o momento de mudanças nos objetivos da Agenda de Desenvolvimento Sustentável pós-2015 da ONU como "[...] oportunidade única para posicionar a igualdade de gênero e o empoderamento das mulheres no centro da agenda global" e admite que diversos processos históricos tornam propício o envolvimento de homens no apoio à solução de problemas sexistas.

Nesse contexto, o ElesPorElas surge como "um movimento de solidariedade pela igualdade de gênero, que envolve homens e meninos como defensores e partes interessadas para quebrar o silêncio, levantar suas vozes e para agir rumo ao alcance da igualdade de gênero" (ONU Mulheres, 2015b, p.1). Esta formulação orienta que os homens assumam um lugar de fala a favor da luta historicamente liderada pelas mulheres. A campanha não propõe que eles assumam o lugar de fala delas, mas é desenvolvida como um convite à cooperação masculina na luta contra o sexismo.

A ONU Mulheres (2015a) considera a desigualdade de gênero como um problema de direitos humanos e acredita que não apenas as mulheres devem discuti-la e combatê-la. A campanha constata que para alcançar a igualdade é preciso empregar a inclusão dos homens nos movimentos contra o sexismo, atestar suas responsabilidades e papeis sobre aspectos machistas presentes na sociedade e visar sobretudo os direitos das mulheres, historicamente negados (ONU Mulheres, 2015a; 2015b; 2015c; 2015d). Entende-se que são necessárias mudanças sociais, culturais e institucionais e que os homens percebam a importância de basear a sociedade em um cenário de igualdade de gênero (ONU Mulheres, 2015a). Desse modo, o ElesPorElas se torna "[...] um esforço global para envolver homens e meninos na remoção das barreiras sociais e culturais que impedem as mulheres de atingir seu potencial e ajudar homens e mulheres a modelarem juntos uma nova sociedade" (ONU Mulheres, 2015c, p.1). Nas palavras de Gasman (2017, p.1-2), o HeForShe:

[...] é um movimento de todas e todos [...] trata-se da elaboração de uma visão compartilhada de que a igualdade de gênero é uma questão de justiça a benefício de todos os seres humanos [...] convida não só as mulheres, mas também os homens para participarem, pois acredita que eles também precisam se tornar parte do movimento para promover os direitos das mulheres, tanto como defensores, quanto como partes interessadas [...] visa promover reflexão e ação sobre a responsabilidade que homens e meninos têm na eliminação de todas as formas de violência e discriminação contra as mulheres e meninas.

A ONU Mulheres (2015a) vê a campanha como a oportunidade de: 1) gerar solidariedade entre homens e mulheres na conjuntura da igualdade de gênero; 2) de envolvê-los, fazendo que se identifiquem com o assunto ao reconhecerem os benefícios de libertar todas/os das opressões machistas e de estereótipos de gênero; e 3) de atentar especialmente à participação do público jovem com o objetivo de dar um novo estímulo ao movimento das mulheres.

No lançamento da campanha, Watson (Emma..., 2014) observa o feminismo como o ideal de igualdade política, econômica e social entre gêneros, a crença de que todos/as devem ter direitos e oportunidades iguais. Ela declara, em contraponto, que já percebeu que o feminismo é visto por muitas pessoas (inclusive mulheres) como um sinônimo de repúdio aos homens. As pesquisas realizadas pela atriz para a produção de sua fala constataram que a palavra "feminismo" às vezes é vista como impopular e que diversas mulheres escolhem não se identificar como feministas. Ela refuta crenças antifeministas ao destacar seus ideais e contar seu processo pessoal para se identificar como feminista. Vale apontar que Gasman (2017, p.3) deixa claro que a ElesPorElas entende o feminismo como "[...] um movimento protagonizado pelas mulheres em defesa dos direitos das mulheres e da igualdade de gênero para todas as pessoas". 
Watson (Emma..., 2014) ainda menciona um pronunciamento de Hilary Clinton sobre os direitos das mulheres, ocorrido em Pequim, em 1997, e ressalta que, na ocasião, apenas 30\% da audiência era composta de homens. Ela questiona: "Como podemos realizar a mudança no mundo quando apenas a metade das pessoas é convidada ou se sente à vontade para participar desta conversa?" (Emma..., 2014). Com essas reflexões principais ela estende as reivindicações das lutas pela igualdade de gênero aos homens e os convida à cooperação por meio da frase que se tornou o slogan da campanha: "Se não você, quem? Se não agora, quando?".

Sobre os lugares de fala, importa destacar que Gasman (2017, p.3) explica que a proposta do HeForShe: "é que os homens olhem para o próprio comportamento e não que assumam o lugar de fala das mulheres". Desse modo, a campanha reivindica que homens defendam e falem sobre as lutas feministas a partir de seus lugares, reconhecendo-os e refletindo sobre eles primeiramente. A campanha visa o protagonismo feminino nas lutas contra o sexismo e argumenta que a solidariedade dos homens é crucial para se alcançar o fim da exploração sexista e da opressão. Gasman (2017, p.3) defende que para contribuir com o feminismo é preciso:

[...] refletir masculinidades positivas e, para isso, é preciso que os homens sejam parte da solução. Não haverá uma transformação para um Planeta 50:50 de igualdade de gênero se não houver um reconhecimento do papel dos homens nesse processo e uma mudança de comportamento deles, que são a metade da população que está ocupando as posições de poder e privilégio. Não só as mulheres, mas também os homens têm as suas escolhas limitadas e o seu comportamento pré-determinado pelos estereótipos de gênero. A questão é que, nessa diferenciação, as mulheres são as maiores vítimas de diferentes formas de violência e desvantagem. Se alcançarmos a igualdade de gênero, todas as pessoas, independente do gênero, terão oportunidades iguais e serão livres para se expressar e fazer suas próprias escolhas.

A reflexão de masculinidades positivas e a orientação tomada pela campanha se desenvolvem intrinsecamente vinculadas à abordagem teórica do feminismo visionário, proposta por bell hooks (2018), reconhecendo que homens são parte necessária para o fim do sexismo: "É urgente que homens levantem a bandeira do feminismo e desafiem o patriarcado. A segurança e a continuidade da vida no planeta exige a conversão feminista dos homens" (hooks, 2018, p.164)'.

Assim, a campanha centra esforços na sensibilização de que o sexismo não é benéfico para ninguém e que os homens precisam ser convocados a estarem junto às mulheres nas lutas contra o sexismo, exploração e opressão. Vale destacar que a campanha é organizada em diferentes estratégias de implementação, o que possibilita alcançar diversos grupos, empresas, universidades, chefes de estado e personalidades.

\section{DESENVOLVIMENTO, IMPLEMENTAÇÃO E ALCANCE DA CAMPANHA}

O HeForShe conta com uma organização previamente estruturada para que haja uma tangível viabilidade de vitória para a meta de combate ao sexismo no planeta. 0 desenvolvimento da campanha em nível global foi possível graças à estrutura organizacional preexistente de escritórios nacionais e regionais da ONU Mulheres, como explica Gasman (2017, p.4):

O HeForShe é um movimento global liderado pela ONU Mulheres e segue a mesma estrutura organizacional da ONU Mulheres, que tem o escritório global em Nova York, os escritórios regionais e nacionais. Desse modo, os escritórios da ONU Mulheres ao redor do mundo estão alinhados com a estratégia desenvolvida pelo time da HeForShe na sede global da ONU Mulheres.

1 É proposital e sugestão da própria bell hooks (2018) a escrita de seu nome em letras minúsculas. 
A ONU Mulheres desenvolveu, até setembro de 2015, o Programa-Piloto de Impacto 10x10x10 como estratégia para implementar a campanha e atingir seus objetivos. Em suma, o programa visou a participação inicial de três âmbitos sociais: governo, setor privado e o público jovem. Promoveu-se o envolvimento de, no mínimo, 10 chefes de Estado, 10 CEO de empresas e 10 reitores de universidades (ONU Mulheres, 2015a; 2015c; 2015d) que se propusessem a identificar abordagens adequadas para enfrentar a desigualdade de gênero na esfera correspondente.

Cada grupo político, empresarial ou universitário tem ações específicas para realizar ao se comprometer com o movimento (ONU Mulheres, 2015a; 2015c; 2015d). Por exemplo, chefes de Estado se comprometem a defender a igualdade de gênero e lançar nacionalmente o ElesPorElas; empresas seguem os Princípios de Empoderamento das Mulheres predefinidos e mobilizam funcionários através da campanha; e universidades implementaram cursos sobre o tema nos campi e em conjunto a outras universidades. 0 Programa-Piloto procurou criar e testar, então, uma base inicial de envolvimento global das pessoas com o ElesPorElas. Vale apontar que Gasman (2017) destaca que centenas de milhares de pessoas em todo o mundo - chefes de Estado, CEO, reitores/as de universidades, professores/as, alunos/as, personalidades globais, e pessoas de diferentes estilos de vida e classes sociais - apoiaram o ElesPorElas e se comprometeram com a igualdade de gênero.

A partir dessas ações, a campanha já viabilizou e ainda oportuniza diversas formas de promoção, engajamento e introdução ao feminismo. Consta-se que a conscientização é um eixo fundamental para o desenvolvimento dos objetivos do ElesPorElas e é feita através de informações no site da campanha, de divulgações midiáticas, além de eventos, palestras e debates promovidos por parceiros/as. Nessa direção, Gasman (2017) relata que o movimento tem sido tema de milhares de eventos ao redor do mundo e de mais de dois bilhões de conversações nas redes sociais.

Para se ter uma dimensão deste alcance: 0 vídeo original do enunciado de lançamento da campanha publicado no YouTube pelo canal oficial e internacional da ONU, o United Nations, foi visto, até a escrita deste texto, 4.555.338 de vezes, apresentando cerca de 107 mil curtidas favoráveis e 5,6 mil desfavoráveis (Emma..., 2014). Somente este dado poderia atestar a relevância do pronunciamento de Watson para o ElesPorElas, mas, além desta reprodução, outras diversas publicações do mesmo vídeo por outros canais ajudam a multiplicar o número, por exemplo: o canal oficial da HeForShe internacional no YouTube indica 2.040.796 visualizações ${ }^{2}$; uma versão publicada em um canal pessoal e independente com legendas em português foi visualizada 422.246 vezes ${ }^{3}$. Muitas outras cópias do vídeo foram publicadas independentemente por diferentes usuários do YouTube e são vistas em vários países. Isto sem contar as inúmeras vezes que o enunciado da atriz foi compartilhado integralmente ou em partes em páginas e perfis de redes sociais, como Facebook, Twitter e Instagram. Ademais, o site da campanha apresenta outros somatórios que vislumbram o alcance em assinaturas, eventos e conversações. Até a escrita deste texto, o site indicava o comprometimento por 2.233.425 assinaturas, a média de 1.300.000.000 de conversas em redes sociais digitais e cerca de 1.100 eventos realizados.

Por outro lado, Gasman (2017) explica que a assinatura no site não é apenas uma maneira de realizar medições, mas também um mecanismo que visa principalmente que os homens acessem o site e se informem sobre igualdade de gênero. Ela verifica que existe dificuldade de contabilizar o envolvimento exato das pessoas com a ElesPorElas e se torna mais viável constatar 0 engajamento através das atividades promovidas (Gasman, 2017, p.2), já que a campanha disponibiliza materiais gratuitamente no site e encoraja diferentes grupos a agirem independentemente em favor igualdade de gênero. 


\section{CONSIDERAÇÕES FINAIS}

É notável que a ElesPorElas demonstra o exercício de um lugar de fala com outro/a que atenta ao protagonismo feminino e convite à cooperação masculina. Contudo, a escrita "ElesPorElas" também pode agregar um sentido hierárquico, masculinista e heteronormativo, inscrito socialmente nas relações de poder e no discurso sobre gêneros ao longo da história: o de que os homens devem cumprir um papel "heroico" e "cavalheiro" com a finalidade defender e auxiliar as mulheres, que seriam vistas como frágeis, indefesas e impotentes; 0 de que eles devem fazer algo por elas, pois seriam incapazes de fazer por si mesmas.

Muitas críticas feitas à campanha se embasam neste viés argumentativo. Tais problematizações são compreensíveis, já que o discurso expressa e permite observar o exercício das relações de poder em diferentes instâncias sociais, como nas hierarquias e heteronormatividades manifestas nas relações de gênero. Mesmo que os objetivos da campanha se orientem pela cooperação dos homens nas lutas lideradas pelas mulheres contra o sexismo, as marcas discursivas da escrita "eles por elas" dão pistas para a percepção de que o movimento da ONU Mulheres não consegue romper integralmente com a lógica masculinista que envolve as relações de poder no âmbito dos gêneros, ao menos não no que tange à concepção que nomeia a campanha.

Entretanto, fica evidente que, em suas diretrizes, a campanha não objetiva que os homens passem a protagonizar as lutas contra o sexismo, tampouco que eles defendam e auxiliem as mulheres por meio do cumprimento de um papel heroico ou cavalheiro por considerarem-nas frágeis e impotentes. De outro modo, pretende que eles tomem consciência da masculinidade tóxica difundida socialmente, das limitações existentes por conta dos estereótipos de gênero que atingem mulheres e homens, que reconheçam o papel masculino para uma real transformação social orientada à igualdade entre gêneros e constatem que precisam integrar a luta como partes também interessadas.

Desse modo, acreditamos que a preposição "por" não é a mais adequada para traduzir a finalidade da campanha, pois faz a ligação subordinativa entre "eles" e "elas" de modo vertical e hierárquico, mesmo que implicitamente. 0 pronome "eles" está acima do vértice, o que indica o exercício da atividade em causa do pronome "elas", que está abaixo, reforçando um ideal patriarcal e masculinista. Outra opção que orientaria para uma horizontalidade e evidenciaria o aspecto solidário e não-hierárquico que a campanha se propõe a transmitir seria a escolha da preposição "com". "Eles Com Elas" já partiria de um tratamento igualitário entre as partes envolvidas, além de demonstrar o sentido de união e de trabalho em conjunto.

Compreendemos que o uso da preposição "com" se adequaria melhor às propostas da campanha e sustenta de modo mais coerente a discussão teórica sobre os lugares de fala ao ter em conta o enfoque horizontal, solidário e não-hierárquico. Isso ainda evitaria a flexão "pelo/a" - contração da preposição por + artigo definido o/a = per + lo - nas construções frasais. Logo, evidenciamos a importância de reflexões sobre o exercício de lugares de fala de um sujeito com outro/a e não por/pelo/a outro/a, conforme sustentado em Gripp e Silveira (2021). Apesar desta construção enunciativa que dá nome à campanha gerar afastamento de algumas pessoas, a análise semiótica paratextual ajuda a evidenciar que os objetivos da ElesPorElas estão alinhados à cooperação masculina nas lutas contra o sexismo.

É importante ressaltar que os homens - sobretudo os brancos e heterossexuais - são quem mais se beneficiaram historicamente e ainda colhem vantagens e usufruem de privilégios diante do sistema patriarcal-capitalista vigente nas sociedades. Quando hooks (1984) aponta a existência de laços que unem as pessoas que lutam coletivamente pela libertação de estruturas opressivas e de dominação, sobretudo o sexismo, ela sustenta que desenvolver um viés crítico sobre o patriarcado não deve conduzir a um ataque na mesma moeda, ou seja, na perpetuação de ódio aos homens. Por outro lado, a autora também destaca que 0 feminismo visionário deve ser compreendido como um movimento amoroso e que seus objetivos de paz, amor, união e justiça 
devem embasar as respostas visibilizadas pelas mídias (hooks, 2018). Entendemos que a HeForShe se desenvolve a partir da perspectiva do feminismo visionário, mobilizando para conscientizar as pessoas sobre pautas feministas e convocando os homens para cooperarem nas lutas.

A proposta da ElesPorElas é frutífera para o debate sobre os lugares de fala, principalmente no contexto empírico de um sujeito ser convocado a assumir um lugar em conjunto nas lutas adscritas à identidade de outro/a, conforme Gripp e Silveira (2021). Ao convocar os homens para que repensem seus lugares privilegiados e se posicionem a favor das lutas pela igualdade de gênero e contra o sexismo, a campanha propõe que eles falem a partir de seus próprios lugares sociais (agora revistos criticamente) e em conjunto às mulheres como favoráveis às lutas feministas. Isto demonstra o uso da estratégia de enunciação dos lugares de fala com outrem embasada na lógica discursiva, em que se observa o caráter produtivo das relações de poder e se evidencia o aspecto dialógico da noção, pois viabiliza a comunicação ao invés de interditá-la.

\section{REFERÊNCIAS}

CONNELL, Raewyn. Gênero em termos reais. São Paulo: nVersos, 2016.

DUARTE, Elizabeth Bastos; CASTRO, Maria Lília Dias. Produção midiática: o ir e vir entre teoria, metodologia e análise. In: BARICHELLO, Eugenia Mariano da Rocha; RUBLESCKI, Anelise (org.). Pesquisa em comunicação: olhares e abordagens. Santa Maria: Facos, 2014. p.67-87.

GASMAN, Nadine. Entrevista sobre a campanha "ElesPorElas". [Entrevista cedida a] Phillipp Dias Gripp. 26 jul. 2017. Disponível em: https://drive.google.com/file/d/1bVklx71yy7FED8kLsachXa1YRDdwCbl_/view?usp=sharing. Acesso em: 16 ago. 2021.

GRIPP, Phillipp Dias; SILVEIRA, Ada Cristina Machado. A ambivalência discursiva e representacional dos lugares de fala. Revista Latinoamericana de Estudios del Discurso, Brasília, DF, v.21, n.1, p.44-61, 2021.

hooks, bell. O feminismo é para todo mundo: políticas arrebatadoras. Rio de Janeiro: Rosa dos tempos, 2018.

hooks, bell. Feminist theory: from margin to center. Boston: South End Press, 1984.

ONU MULHERES. Movimento ElesPorElas: visão geral, 2015a. Disponível em: http://www.onumulheres.org.br/wp-content/ uploads/2015/03/ElesPorElas_visao_geral.pdf. Acesso em: 12 ago. 2021.

ONU MULHERES. Movimento ElesPorElas: kit de Ação, 2015b. Disponível em: https://www.onumulheres.org.br/wp-content/ uploads/2015/03/ElesPorElas_kit_acao.pdf. Acesso em: 12 ago. 2021.

ONU MULHERES. Movimento ElesPorElas: impactando universidades, 2015c. Disponível em: http://www.onumulheres.org. br/wp-content/uploads/2015/03/ElesPorElas_universidades.pdf. Acesso em: 12 ago. 2021.

ONU MULHERES. Movimento ElesPorElas: impactando empresas, 2015d. Disponível em: https://www.onumulheres.org.br/ wp-content/uploads/2015/03/ElesPorElas_empresas.pdf. Acesso em: 17 fev. 2021.

RIBEIRO, Djamila. O que é lugar de fala? Belo Horizonte: Letramento; São Paulo: Justificando, 2017. 
EMMA Watson at the HeForShe Campaign 2014. [S.l:: s.n.], 2014. 1 vídeo (13 min). Publicado pelo canal Nações Unidas. Disponível em: https://www.youtube.com/watch?v=gkjW9PZBRfk\&t=54s. Acesso em: 18 fev. 2021.

Artigo recebido em 29.04.2021 e aprovado em 09.08.2021. 